\title{
Editorial
}

\section{The mission of the National Institute of Occupational Safety and Health, Japan (JNIOSH)}

The mission of our institute, the National Institute of Occupational Safety and Health, Japan (JNIOSH), is to reduce occupational accidents, and diseases at work, through scientific investigation and research activities. Furthermore, we also strive to improve the work environment, to ensure the safety and health of workers and create a comfortable work environment.

In my experience, the two subjects described below well explain the mission of JNIOSH and its role.

\section{The Policy Evaluation and Evaluation of Incorporated Administrative Agencies}

Over the last decade, research institutes such as ours have undergone a transformation from national research institutes to incorporated administrative agencies. During and after this transformation we have been subjected to administrative reforms including: 1) Screenings conducted by the Government Revitalization Unit, 2) Screenings within the Ministry of Health Labour and Welfare (MHLW), 3) Policy evaluations and Incorporated Administrative Agency evaluations conducted by the Ministry of Internal Affairs, Communications, 4) Expert panel meetings, etc.

All objective suggestions and opinions received from external sources were very valuable, and many of them were important for reflecting on our own work. We, at JNIOSH, believe that we have reformed ourselves based on these suggestions.

When I was working in the Research Planning Department of JNIOSH, I attended the Commission on Policy Evaluation and Evaluation of Incorporated Administrative Agencies in 2010.

One of the members of the Commission was a university professor who had lost one of his relatives in an occupational accident. He said that he fully understood the importance of JNIOSH because of his relative's accident. Opinions received from him and other members of the committee included "It is certainly important to write academic research papers, but JNIOSH also needs to compre- hend the needs of the field and conduct investigations that are really needed to reduce occupational accidents," and "Targets of research projects should be set in numerical terms, such as the extent of reduction in occupational accidents. We know that it may not be possible for JNIOSH to accomplish all this by itself, but we would still like it to indicate targets in numerical terms, such as the extent of reduction in occupational accidents."

The "Recommendations" (Outline) released by the Commission in December 2010 are as follows ${ }^{1)}$ :

1) Researchers should actively visit sites of actual work, observe the issues, problems and work environment there, and present them accurately in their selection of research topics and other research activities with the objective of accurately dealing with issues concerning the prevention of occupational accidents.

2) Research results should indicate the degree of compliance with laws and regulations on occupational safety and health as well as numerical targets, such as the extent of reduction in occupational accidents, and the degree of their achievement should also be strictly evaluated.

From these suggestions, I understand that the mission of JNIOSH is to keep researchers at a university-level of academic competence in their respective fields of study, and at the same time we need to possess deep knowledge regarding occupational safety and health, contribute to occupational safety and health measures, ultimately playing a thorough role in reducing occupational accidents. We have sincerely accepted the suggestions as the guiding principles of JNIOSH and have incorporated them in our mid-term, yearly and other plans.

\section{The 13th Occupational Safety \& Health Program}

Occupational safety and health administration is carried out along the lines of the Occupational Safety \& Health Program ${ }^{2,3)}$, which is stipulated every five years by the MHLW. The 13th Occupational Safety \& Health Program was recently formulated, and indicates the direction for oc- 
cupational safety and health for the next five years starting from FY2018. This plan states the following in relation to JNIOSH:

1) Promoting measures based on scientific evidence and international trends

- Collaborate with the National Institute of Occupational Safety and Health, Japan (JNIOSH) and promote research on safety and health related factors such as industrial machinery, chemical substances, etc. in order to further administrative measures based on scientific evidence.

- Administrative measures for safety and health should be promoted based on knowledge obtained overseas and via current trends relating to measures. Efforts should be made to obtain the latest knowledge and gather information on international trends in order to ensure consistency with international measures and regulation

2) Studying measures for preventing serious accidents

- Collaborate with JNIOSH to investigate the causes of serious accidents and study measures to prevent them.

3) Identifying conditions leading to overwork-related deaths and other issues, and investigating preventive measures

- Continuously gather and analyze data at the Research Center for Overwork-related Disorders at JNIOSH. Objectively measure and analyze data on the relation between overwork and overwork-related deaths as well as other issues through epidemiological research and investigation, and study preventive measures based on the results.

We frequently debate the outcomes of these directions for JNIOSH and have no doubt that, in the end, we must contribute to the reduction of occupational accidents, as suggested in the recommendations from the aforementioned Commission. However, as suggested by the Commission, this cannot be achieved by JNIOSH alone. As stated in the 13th Occupational Safety \& Health Program, it is essential to connect the results of JNIOSH's scientific research with the formulation of policies on safety and health.

For this purpose, it is necessary to strategically conduct surveys and research activities on accidents while keeping in mind on-site and administrative needs, and collaborating with administrative bodies to ensure that the results connect with the formulation of administrative policies.

Additionally, it can be said that there is a need to play a leading role in Japan and the world through our research activities. Along with research carried out by the Research Center for Overwork-related Disorders, established in JNIOSH in 2014, we are conducting joint studies in other safety and health-related fields in cooperation with multiple universities and companies, and promoting research that satisfies our function as a core entity in safety and health. Thus, there is a need to strategically expand such research activities. Moreover, we expect a synergistic effect with clinical studies by rosai hospitals, which provide medical care for workers, and other institutions.

In terms of monitoring international trends, it is important to understand the actual condition of safety and health, policy measures and strategies all over the world, as well as strengthening collaboration with occupational safety and health institutions across the world to promote research efficiency.

We believe occupational accidents can only be reduced through the joint efforts of research institutions, etc. within and outside Japan. We will devote ourselves to contributing to the improvement of the academic and practical levels of researches into occupational safety and health in Japan and the world through this journal, Industrial Health, and other activities. We will also endeavor to build an environment in which persons from the field of occupational safety and health can work together all over the world.

We at JNIOSH will continue to endeavor to be a research institute that is universally recognized as a core entity in the pursuit of zero accidents and worker's wellbeing in the field of occupational safety and health research.

\section{References}

1) Ministry of Health, Labour and Welfare (2010) Outline of the direction of recommendation concerning major administrative work and revision, Independent Administrative Institution Evaluation Committee Research Study Group, (51st). http:// www.mhlw.go.jp/stf/shingi/2r9852000000zmqe.html.

2) Ministry of Health, Labour and Welfare (2013) The 12th Occupational Safety \& Health Program. http://www.mhlw. go.jp/stf/seisakunitsuite/bunya/koyou_roudou/roudoukijun/ anzen/anzeneisei21/index.html.

3) Ministry of Health, Labour and Welfare (2018) The 13th Occupational Safety \& Health Program. http://www.mhlw. go.jp/stf/seisakunitsuite/bunya/0000197308.html.

\section{Yasuo TOYOSAWA, PhD}

